\title{
NARRATIVAS DE CRIANÇAS SOBRE O SABER/FAZER EM FESTAS AMAZÔNICAS: \\ O CASO DA MARUJADA DE SÃO BENEDITO E SÃO SEBASTIÃO EM TRACUATEUA/PA
}

Dilma Oliveira da Silva ${ }^{1}$

Nazaré Cristina Carvalho ${ }^{2}$

\begin{abstract}
RESUMO
O estudo tem como objetivo analisar os saberes e os fazeres vivenciados pelas crianças durante a festa da marujada no município de Tracuateua/PA. A problemática fomentada norteou-se pela seguinte pergunta: qual a percepção das crianças da marujada de Tracuateua/PA sobre os saberes/fazeres dessa festividade? Para isso, foi necessário discutir as categorias cultura, educação, saberes e infância sobre novos olhares na perspectiva da cultura representada como "teia de significados" construídos nas relações sociais dos homens; a educação como uma "fração dessa cultura" e que pode ser desenvolvida em diferentes lugares com diversos grupos sociais; os saberes enquanto um aprendizado transmitido entre gerações numa heterogeneidade de fazer; a infância foi analisada à luz da "sociologia da infância", compreendendo a criança como protagonista de suas vivências. Este estudo teve como intérpretes 16 (dezesseis) crianças, sendo 10 (dez) meninas e 6 (seis) meninos, com faixa etária entre 6 (seis) e 12 (doze) anos de idade, participantes da festa. O percurso metodológico foi caracterizado pela abordagem qualitativa com técnicas de pesquisa como rodas de conversas, observação, diários de campo, registros fotográficos e a dinâmica com desenhos. Dessa forma, partindo da diversidade de conhecimento construídos no cotidiano da marujada identificou-se saberes e fazeres inerentes a festa vivenciados e partilhados do/pelo movimento entre marujos e marujas de diferentes gerações por meio da escuta, da observação e da oralidade.
\end{abstract}

Palavras-chave: Cultura. Saberes. Marujada. Narrativas de Criança.

\section{CHILDREN'S NARRATIVES CONCERNING THE KNOWING-DOING OF AMAZONIAN FESTIVITIES: THE CASE OF MARUJADA DE SÃO BENEDIT AND SÃO SEBASTIÃO IN TRACUATEUA/PA}

\begin{abstract}
The study aims to analyze the knowledge and practices experienced by children during the marujada party in the city of Tracuateua / PA. The problem raised was guided by the following question: what is the perception of the children of the marujada from Tracuateua / PA on the knowledge / practices of this festival? For this, it was necessary to discuss the categories culture, education, knowledge and childhood about new perspectives from the perspective of culture represented as a "web of meanings" constructed in the social relations of men; education as a "fraction of that culture" that can be developed in different places with different social groups; knowledge as a learning transmitted between generations in a heterogeneous way of doing; childhood was analyzed in the light of "childhood sociology", understanding the child as the protagonist of their experiences. This study had as interpreters 16 (sixteen) children, 10 (ten) girls and 6 (six) boys, aged between 6 (six) and 12

\footnotetext{
${ }^{1}$ Doutoranda do Programa de Pós-Graduação pela Universidade Federal do Pará (UFPA); Mestre em Educação pela Universidade do Estado do Pará (UEPA); Licenciada em Geografia e professora de Geografia na Secretaria Estadual do Pará. E-mail: dilmaanika@gmail.com.

${ }^{2}$ Doutora em Educação Física e Cultura (UGF2006); Mestra em Educação (UNIME/SP 1998). Possui Estágio PósDoutoral em Educação (PUC/RJ 2014). É licenciada em Educação Física e Ciências Sociais. Atualmente é professora adjunta da Universidade do Estado do Pará (UEPA)/ Departamento de Artes Corporais e Programa de Pós-Graduação (mestrado) em Educação, integrando a Linha de Pesquisa Saberes Culturais e Educação na Amazônia. E-mail: dilmasilva@ymail.com.
} 
(twelve) years of age, participating in the party. The methodological path was characterized by a qualitative approach with research techniques such as conversation circles, observation, field diaries, photographic records and the dynamics with drawings. Thus, based on the diversity of knowledge constructed in the daily life of the marujada, knowledge and actions inherent to the party were identified, experienced and shared by / by the movement between sailors and sailors of different generations through listening, observation and orality.

Key Words: Culture. Knowledge. Marujada. Child narratives.

Data de submissão: 20.10 .2020

Data de aprovação: 26.12 .2020

\section{INTRODUÇÃO}

Este artigo teve como objetivo analisar as narrativas de crianças sobre os saberes e fazeres em festas amazônicas com o recorte para a festividade da marujada de São Benedito e São Sebastião em Tracuateua/PA. Para isso, foi necessário discutir as categorias teóricas como: cultura, educação, saberes e infância sobre novos olhares, numa perspectiva de que a cultura é uma "teia de significados" que são construídos nas relações sociais dos homens; a educação como uma "fração dessa cultura" e que pode ser desenvolvida em diferentes lugares com diversos grupos sociais. A infância, foi analisada à luz da "sociologia da infância", compreendendo a criança como protagonista de suas vivências.

Brandão (2002, p. 09) destaca que: "Não há uma única forma, nem um único modelo de educação, a escola não é o único lugar em que ela acontece e talvez nem seja o melhor; o ensino não é sua única prática e o professor não é seu único praticante". A educação para o autor é uma maneira do modo de vida dos diversos grupos sociais que criam e recriam sua cultura. Sendo assim, a educação também pode ser encontrada nos diversos saberes populares perpassando por um processo socioeducativo.

De acordo com Geertz (2014, p. 04), o entendimento sobre a cultura deve partir do contexto de que: "O homem é um animal amarrado a teias de significados que ele mesmo teceu" e que vem criando e recriando suas maneiras de viver, de acordo com suas necessidades, pois é necessário compreender que a cultura não se explica uniformemente pelas bases naturais, mas, principalmente por suas bases sociais condicionadas a vida do homem às suas formas de viver e interpretar o mundo.

$\mathrm{O}$ autor ainda menciona que os fenômenos culturais que pertencem a sociedade, são penetrados por teias de signos e significados, tecidas pelos próprios homens e mulheres em suas ações, numa relação dinamicamente interpretativa e, por isso, entende que a cultura precisa de uma base teórica que supra o discurso descritivo e superficial sobre ela. Como ele mesmo ressalta:

O conceito de cultura que eu defendo, é essencialmente semiótico. Acredito [...] que o homem é um animal amarrado a teias de significados que ele mesmo teceu, assumo a cultura como sendo essas teias e suas análises; portanto, não como uma ciência experimental em busca de leis, mas como uma ciência interpretativa à procura de significados. (GEERTZ, 2014, p. 04).

A essência dessa semiótica, defendida por Geertz (2014) analisa a cultura como um conjunto de sistemas que poderia se chamar teias de significados, e nessas teias passam os mais diferentes tipos de produção cultural. Através da compreensão desses significados e sua interrelação, pode se constituir uma ciência interpretativa ou obter conceitos mais definidos de cultura.

As expressões da criança de forma geral, como: "As ideias, os valores, e as emoções 
são produtos culturais manufaturados", ou seja, são tecidas pelas mãos dos sujeitos, sendo que para a compreensão dessas expressões ou desses signos é necessário compreender o significado e chegar até "os conceitos específicos das relações entre eles" (GEERTZ, 2014, p. 36,37). É por isso que pretendemos compreender o que pensam as crianças sobre a marujada de Tracuateua/PA, e depois, analisar os saberes que perpassam essa festa e, consequentemente analisar as relações de aprendizagem desses saberes com os intérpretes dessa pesquisa.

Outro ponto importante para essa pesquisa são as contribuições sobre cultura do historiador inglês Thompson (1995, p. 19), uma vez que ele, também concebe a cultura numa perspectiva discursiva como fenômeno social, interpretando os processos sociais nos quais, e pelos quais, "as formas simbólicas permeiam o mundo social", de modo crescente e generalizado.

Para o autor conhecer a cultura na reconstrução das experiências das pessoas comuns; é compreender o passado à luz de nossas próprias experiências e da experiência dos outros, considerando a subjetividade do homem. Por meio dessa subjetividade os fenômenos culturais como os comportamentos, os valores, as condutas, os costumes, enfim, a cultura do homem poderia ser analisada, ou melhor, as culturas, no sentido de que ela se refere a uma realidade específica. Por isso Thompson (1995), diz que o estudo dos fenômenos culturais poderia ser pensado e analisado numa visão histórica e social:

Pode ser pensado como o estudo das maneiras como expressões significativas de
vários tipos são produzidas, construídas e recebidas por indivíduos situados em um
mundo sócio histórico. Pensado dessa maneira, o conceito de cultura se refere a uma
variedade de fenômenos e a um conjunto de interesses que são, hoje, compartilhados
por estudiosos de diversas disciplinas, desde a sociologia e antropologia até a história
e a crítica literária. (THOMPSON, 1995, p.165).

Ao analisar o termo cultura, Thompson (1995) apresenta três tipos de conceitos construídos ao longo da história para apresentar sua própria visão a respeito dessa concepção cultural, tais como: a clássica, a descritiva e a simbólica. A clássica faz referência à cultura como um processo intelectual ou espiritual que se diferencia sob certos aspectos da civilização. A descritiva, seria um variado conjunto de valores, crenças, costumes, convenções, hábitos e práticas características de uma dada sociedade específica ou de um período histórico (THOMPSON, 1995, p.166). E a simbólica, por sua vez, culminaria nos "fenômenos culturais [...] são fenômenos simbólicos e o estudo da cultura está essencialmente interessado na interpretação dos símbolos e da ação simbólica" (THOMPSON, 1995, p.166).

Nesses três tipos de conceitos de cultura apresentados, podemos perceber que eles culminam nas práticas sociais desenvolvidas pelos homens no decorrer de sua história, que ao longo do tempo vai sendo moldada de sentidos e significados. Assim, a festa da marujada em Tracuateua/PA está imersa nesse aspecto simbólico, por ser palco de uma manifestação que traz, na sua história, inúmeros sentidos e significados inscritos em seus saberes e fazeres, por isso deve ser vista como um elemento cultural que está condicionada às práticas sociais que revelam, por meio dos saberes, a vivência e a experiência desse grupo.

Aqui vamos considerar o que defende Charlot (2013, p. 162) quando apresenta a ideia de heterogeneidade do saber. Para ele, essa ideia é fundamental na relação do saber, uma vez que não existe uma única forma de aprender, e não existem carências na aprendizagem. $\mathrm{O}$ que existe são outras "formas de se relacionar com o mundo, outro tipo de vínculo com o mundo, outra forma de entrar no processo de aprender"

Brandão (2002) assinala seu conceito de cultura afirmando que:

Somos o que criamos para efemeramente nos perpetuarmos e transformarmos a cada instante. Tudo aquilo que criamos a partir do que nos é dado, quando tomamos as coisas da natureza e as recriamos como os objetos e os utensílios da vida social, 
representa uma das múltiplas dimensões daquilo que, em uma outra, chamamos de cultura. (BRANDÃO, 2002, p. 22).

Nas análises de Brandão (2007), a sociedade está estruturada em códigos sociais de inter-relação entre seus membros e entre os de outra sociedade. Estão imersos em costumes, princípios, regras de modos de ser estabelecidos em leis escritas ou não, de forma a agir sobre a vida e o crescimento da sociedade, tanto no sentido de suas forças produtivas como no desenvolvimento de seus valores culturais.

Nesse sentido será importante pesquisar o saber/fazer da festa da marujada para a criança, pois estas serão vistas e ouvidas como indivíduos que dão significados para as suas práticas desenvolvidas nessa manifestação, uma vez que elas vivem e compartilham suas experiências nesse contexto da festa. Sendo assim, as crianças serão percebidas como agentes participativos da sociedade em que vivem e, portanto, como homens e mulheres que dividem suas "experiências e suas concepções".

Trazer a criança para a pesquisa científica como protagonista de sua vivência e história, é compreender a sociologia da infância, que apresenta novos discursos e conceitos acerca da criança, como produtora de cultura e, concebida como forma específica de construção de conhecimento, comunicação e expressão (SARMENTO, 1997).

\footnotetext{
A Sociologia da Infância propõe o estabelecimento de uma distinção analítica no seu duplo objeto de estudo: as crianças como atores sociais, nos seus mundos de vida, e a infância, como categoria social do tipo geracional, socialmente construída. A infância é relativamente independente dos sujeitos empíricos que a integram, dado que ocupa uma posição estrutural. (SARMENTO, 1997, p. 07).
}

$\mathrm{Na}$ perspectiva da Sociologia da Infância, as crianças apresentam expressões interpretativas e atitudes que ajudam a compreender elementos de transformações e maneiras de ver e viver das sociedades, pois é um campo de estudo que se propõe a construir a infância como "objeto sociológico", assim como ela "compreende a criança como objeto de investigação, contribuindo para o próprio conhecimento não apenas da infância, mas como uma categoria social" (ALVES, 2014, p. 37).

Cohn (2005) aborda em suas ideias que a infância é uma fase de construção de aprendizagens em que a criança é um ser ativo e possuidor de um papel importante nas relações sociais, visto que ela é "atuante é aquela que tem um papel ativo na constituição das relações sociais em que se engaja, [...] não sendo, portanto, passiva na incorporação de papéis e comportamentos sociais" (CONH, 2005, p. 28).

Nessa perspectiva e discussão a criança é um sujeito que interage com sua realidade, um ser que, ao participar das interações e relações por meio da comunicação com seus pares, vai construindo a sua identidade e a sua subjetividade.

Para uma análise consistente das narrativas de crianças sobre o fazer/saber da marujada, o artigo está dividido em quatro seções: a primeira consiste nas escritas introdutórias levando em consideração a apresentação do objeto de estudo em uma perspectiva teórica com as categorias cultura, educação, saberes e infância. A segunda, faz uma breve análise do caminho percorrido e as técnicas de pesquisa utilizadas com recorte para a marujada de Tracuateua-PA. A terceira, mostra as principais características da festa da marujada destacando sua origem. A quarta, trata das narrativas das crianças sobre os saberes e fazeres inscritas na festa da marujada de Tracuateua/PA.

\section{O CAMINHAR DA PESQUISA: PERCURSO METODOLÓGICO}

O referido estudo sobre narrativas de crianças sobre festas amazônicas fez um recorte para obtenção de dados por meio da festa da marujada de Tracuateua/PA. Este é um 
município localizado na região do salgado, especificamente na mesorregião Nordeste do Pará, pertencente a microrregião bragantina. Territorialmente contém uma área de $936,1 \mathrm{~km}^{2}$. Teve sua origem com a construção da ferrovia Belém-Bragança por volta de 1908.

Figura 1- Mapa de localização do município de Tracuateua- PA na Amazônia Legal

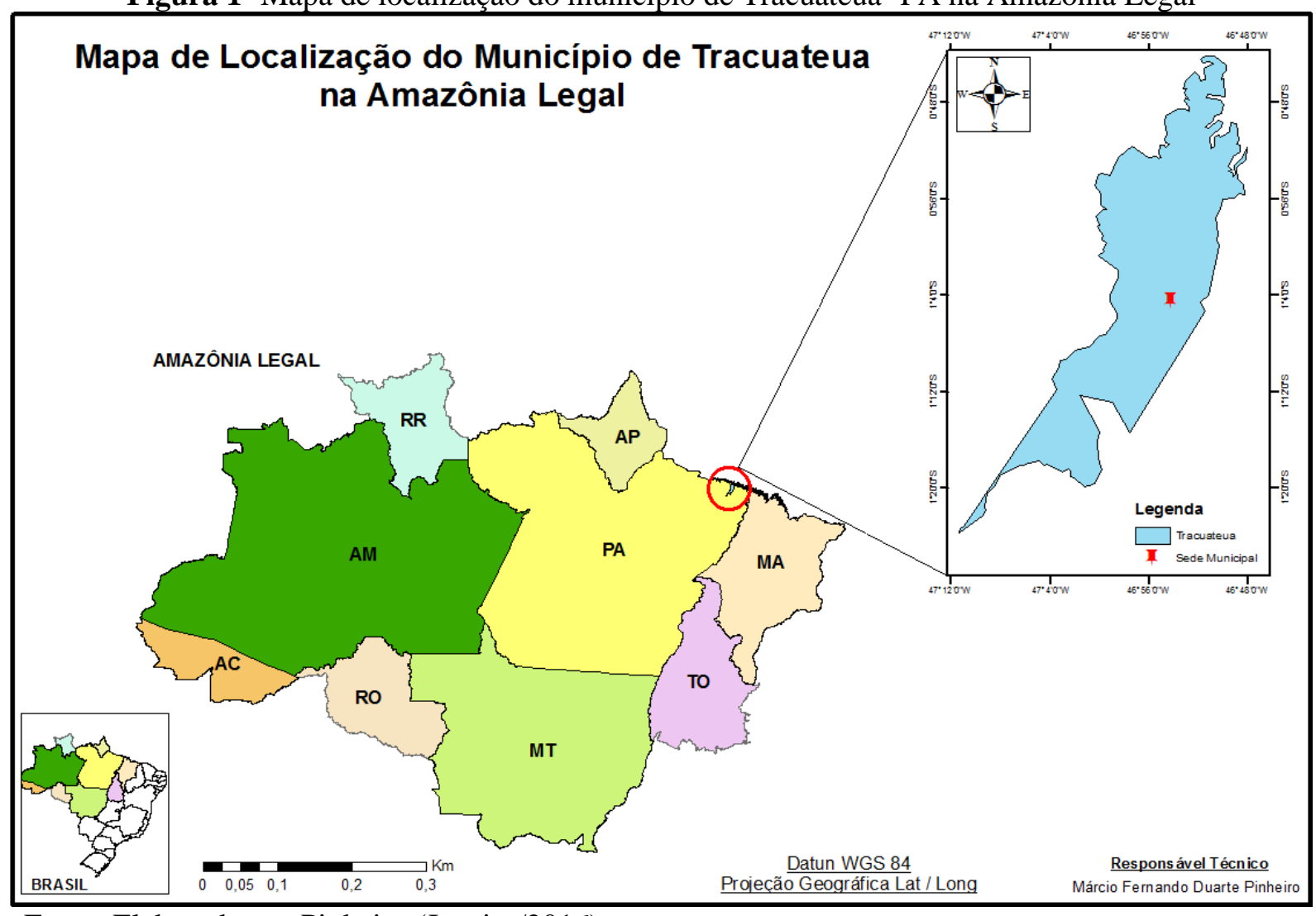

Fonte: Elaborado por Pinheiro (Janeiro/2016)

Tracuateua conta com aproximadamente 32.000 habitantes. Distribuídos entre a zona urbana e rural do município. Estas unidades locais, limita-se a leste com o município de Bragança; ao sul com o município de Santa Luzia do Pará; ao norte com o oceano Atlântico; a oeste com os municípios de Capanema e Quatipuru. Está localizado a 196 quilômetros da capital do estado do Pará - Belém. Foi desmembrado de Bragança em 1994, mas só se tornou município dois anos depois, em 1996. Elevado à categoria de município continuando com a denominação de Tracuateua, pela lei estadual $\mathrm{n}^{\circ} 5858$, de vinte e nove de novembro de mil novecentos e noventa e quatro (29/09/1994), desmembrado de Bragança (IBGE, 2016).

O município concentra muitos encantos festivos, dentre eles está o círio de Nossa Senhora de Nazaré que expressa a manifestação de fé das famílias católicas e a festa da marujada, outra manifestação de devoção e fé que encanta e contagia os participantes, e os que somente apreciam. Essa festa da Marujada é realizada e apresentada no salão conhecida como "Templo ou Salão da Marujada", localizado no centro da cidade ao lado da praça principal, conforme figura abaixo: 
Figura 2 - Localização do salão da Marujada em Tracuateua/PA

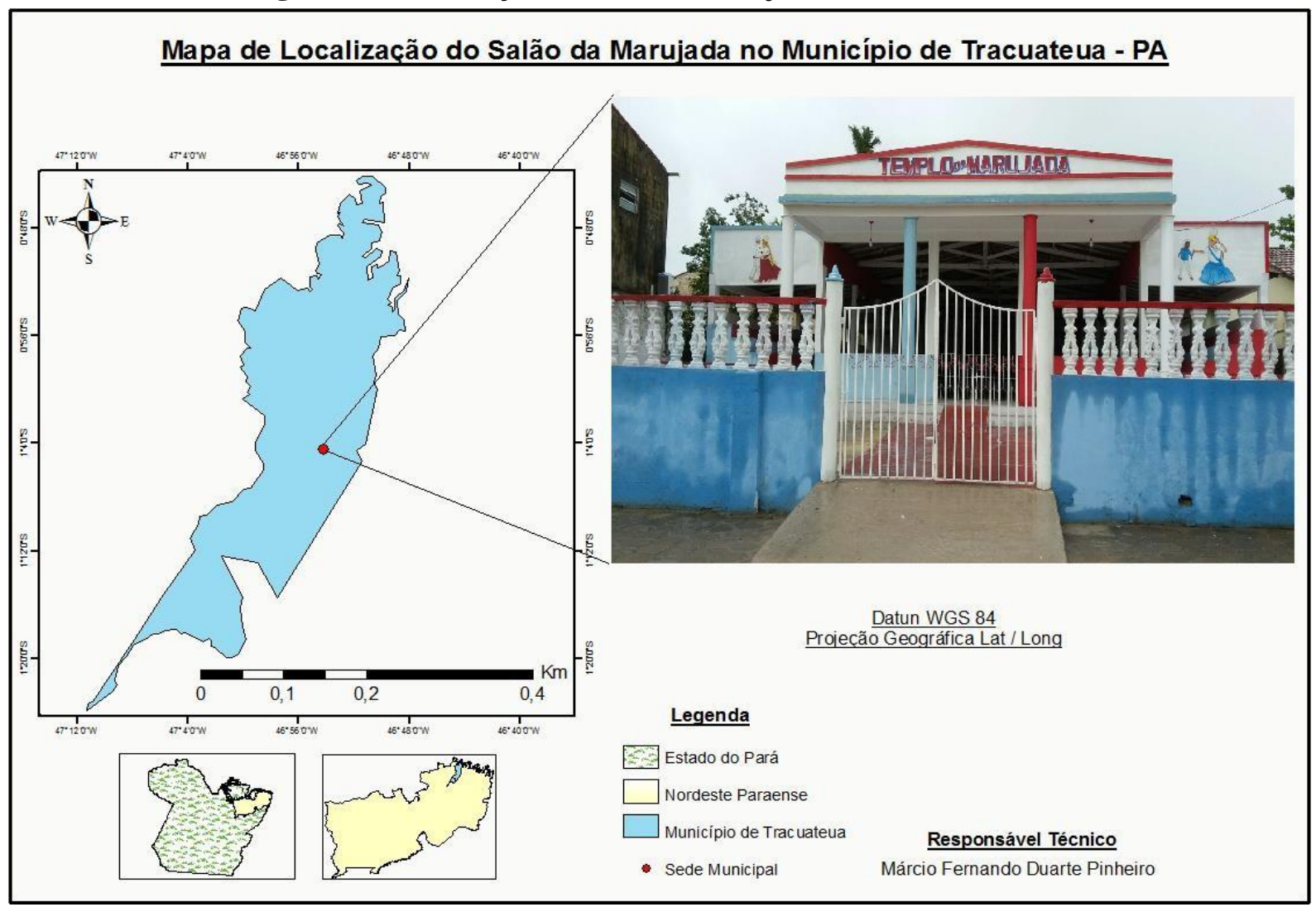

Fonte: Elaborado por Pinheiro (Janeiro/2016)

A partir do recorte da pesquisa teve-se a preocupação de seguir os princípios da Abordagem Qualitativa (MINAYO, 2015), por acreditar que, além de responder questões bem particulares, ela trabalha com o sentido e o significado, nos mais variados universos.

Por considerar que os intérpretes deste estudo são as crianças, isso sinaliza um maior dinamismo para coleta dos dados. Dessa forma, procuramos não delimitar a pesquisa a uma única técnica de coleta de dados, para isso escolhemos: a) a observação participante; b) a roda de conversa; c) o diário de campo; d) o registro fotográfico e d) a técnica do desenho. Esta última somente como uma dinâmica de aproximação com as crianças e não como técnica de análise. Assim, tais técnicas possibilitaram a compreensão dos processos ritualísticos, bem como da circulação de saberes vivenciados na marujada (LAVILLE; DIONNE, 1999, p.176).

Para o tratamento e análise dos dados, foi utilizada a técnica de análise de conteúdo, que trata de um meio de recursos metodológicos que se aperfeiçoam sempre e que se aplicam a diferentes falas e discursos. Esta técnica permite o tratamento das informações com objetivos bem definidos e que servem para desvelar o que está oculto no texto. A Análise de Conteúdo "atua sobre a fala [...]. Ela descreve, analisa e interpreta as mensagens/enunciados de todas as formas de discurso, procurandover o que está por detrás das palavras" (BARDIN, 1994, 58).

É importante lembrar que essa pesquisa também se preocupa com o que diz respeito aos seus aspectos éticos, para isso procuramos nos assegurar e obedecer ao que rege a Resolução 196/96, da Organização Mundial da Saúde - OMS, garantindo o anonimato em relação aos nomes verdadeiros dos sujeitos no Consentimento Livre e Esclarecido (TCLE) para as crianças e para os seus responsáveis, deixando claro os procedimentos no que diz respeito aos sujeitos menores de idade, os quais fazem parte deste estudo.

Nesse sentido nos alertam Oliveira e Motta Neto (2011, p. 13) ao abordarem os cuidados éticos na pesquisa, pois "assumir responsabilidade na e com a pesquisa é assumir a 
presença do outro, respeitando-o como pessoas e cidadão". Nisso também nos preocupamos com o que defende Kramer (1994, p. 32), pois, a decisão de participar é uma opção da criança "que não deve ser pressionada [...] e que definem em comum acordo com o pesquisador, os nomes, fictícios ou não, a fim de resguardar a privacidade/identificação".

\section{A FESTA DA MARUJADA: PRINCIPAIS CARACTERÍSTICAS DE SUA ORIGEM E TRADIÇÃO}

A marujada é uma festa de caráter religioso que se faz presente em algumas partes do Brasil, no estado do Pará, como Bragança, Tracuateua, Augusto Correa, Primavera e Quatipuru com algumas características semelhantes como os rituais das danças, a louvação aos santos e a indumentária; assim como existem aspectos que as diferenciam em seus significado que é constatado no estudo de Amorim (2008, p. 26), e ainda em um estudo realizado pelo Instituto de Artes do Pará, pelo autor Silva (2006), a existência da festa da marujada também no município de Ananindeua.

Nos estudos de Silva (1981) intitulado "Contribuições ao Estudo do Folclore Amazônico na Zona Bragantina" a Marujada de Bragança, como culto religioso, está ligada a Irmandade de São Benedito no Pará, caracterizada como festa religiosa. Ela teria seu marco histórico e sua origem, em Bragança/PA, provavelmente "no século XVIII (1798), com a permissão dos senhores brancos aos seus escravos para exaltar e apreciar São Benedito" (SILVA, 1981, p. 32). Essa permissão dada aos escravos realizaria os seus rituais em louvor à São Benedito, formando assim a organização de uma irmandade e, partir daí acontece a primeira festa e ocorre o primeiro compromisso com o Estatuto da referida irmandade.

A origem dessa festa é vinculada à um contexto histórico da colonização de grande concentração de quilombos que se estendiam de Bragança a Ourém, no estado do Pará. Desse contexto resultaram muitas manifestações de origens negras africanas, pois em Bragança e seus arredores concentravam atividades agrícolas a qual proporcionou um fluxo de mão de obra de escravos para tal região.

\footnotetext{
A grande prosperidade da região de Bragança e entorno, ocasionada pela lavoura de produtos agrícolas, notadamente mandioca, arroz, feijão, tabaco, milho e arroz a produção de gado e peixe, propiciou um grande fluxo de escravos para a mão de obra entre os séculos XVIII e XIX. Sendo assim, a região bragantina foi notada por representar uma fronteira com a Província do Maranhão, com a entrada de escravos dali e de seus engenhos, de suas lavouras, de suas minas de ouro. É natural assim nesse contexto que as tensões entre senhores e escravos fossem mais frequentes e para controlar essas tensões existiras estratégias como as permissões de criação de irmandade entre os negros pelos seus senhores. (FERNADES, 2011, p.58-59).
}

É, portanto, neste cenário de inquietude e aflição entre senhores e pessoas escravizadas que surge a Festa da Marujada em Bragança/PA. Contexto no qual eram expressas grades tensões entre senhores escravizados, sendo a legalização da irmandade de São Benedito uma permissão e forma de controlar tais inquietudes entre pessoas escravizadas no período colonial.

Silva (1997) esclarece que foi especificamente no dia 03 de setembro de 1798, a pedido de 14 pessoas escravizadas, os senhores permitiram que fosse organizada a irmandade da marujada de São Benedito de Bragança. Em gratidão à graça alcançada, os escravos saíram às ruas de Bragança dançando em frente às casas de seus senhores, fazendo evoluções coreográficas. Tal fato repetiu-se com novos agradecimentos nos anos seguintes dando origem à marujada, manifestação atrelada à esta de São Benedito, comportando o sagrado ao popular.

Sendo permitida essa irmandade, os negros começaram a dançar de casa em casa de 
seus irmãos com a imagem do Santo em comemoração a legitimidade de sua irmandade. A partir daí essa festa foi sendo repassada de geração a geração fazendo louvores ao santo padroeiro, ganhando uma nova roupagem e renovando e incluindo alguns rituais sem perder, é claro, sua originalidade negra e africana.

A marujada é caracterizada como uma dança de caráter religioso, formada por homens e mulheres, chamados de marujos e marujas, que dançam em devoção ao Santo. Nesse sentido, Silva (1997), apresenta a marujada como dimensão simbólica com ritual de dança apresentada na festa de São Benedito como um momento que privilegia a construção da identidade de um grupo especifico, no contexto cultural da festa e na sociedade em que esta manifestação está presente.

Sobre a origem da marujada de Tracuateua, nos informou o presidente da Associação de São Benedito e São Sebastião de Tracuateua (AMSSSBT) e vice capitão da marujada, que nesse município, essa festa foi fundada em junho de 1946, pelo vereador e comerciante, José Olegário Pinheiro, conhecido como José Maranhense. O mesmo apreciava muito essa festa e solicitou ao presidente da Irmandade de Bragança, que fosse permitido uma apresentação no ano de 1946 na vila de Tracuateua. Com o pedido concedido, a comunidade de Tracuateua, recebeu pela primeira vez uma apresentação dos marujos e marujas de Bragança.

No entanto, no ano seguinte, a irmandade de Bragança não enviou seus marujos e marujas para outra apresentação, sob alegação de falta de recursos, foi então que a comunidade tracuateuense decidiu formar e fundar sua própria festa da marujada nos mesmos moldes da apresentação Bragantina com devoção a São Benedito e São Sebastião. Esse último faz parte da Festividade porque é Santo Padroeiro do Município de Tracuateua. E assim se realiza no município as homenagens aos santos padroeiros nos dias 19 e 20 de janeiro.

Sobre a origem da marujada de Tracuateua, Reis (2015, p. 14) destaca as contribuições do historiador Antônio Jorge da Silva, ao descrever que a marujada nesse município tem relações com os seguintes aspectos:

\footnotetext{
[...] proveio do fato de os irmãos portugueses Augusto e Antônio Pio, ao virem do Rio de Janeiro, trouxeram o culto de São Sebastião, realizado no dia 20 de Janeiro, para a localidade de Tracuateua. [...] o vereador José Olegário Pinheiro pediu à marujada de Bragança que dançasse durante os festejos de São Sebastião. A partir daí, ficou a prática de "a Marujada de Bragança" dançar no dia 19 de janeiro, antes da festa do santo padroeiro, São Sebastião. Porém, houve um ano em que a Marujada de Bragança não pode participar da festividade de Tracuateua por falta de condução para os marujos. Como já estava tudo organizado, José Olegário pediu a um grupo de dez marujos, residentes na cidade, mas que faziam parte da irmandade de Bragança, que os substituísse. Após esse contratempo, a comunidade resolveu fundar sua própria irmandade aos moldes da bragantina. Assim, em 9 de junho de 1946, foi criada a Marujada de Tracuateua. (REIS, 2015, p.14).
}

Nesse sentido, podemos perceber e analisar que a origem da marujada de Tracuateua tem influências da marujada de Bragança, visto que essa manifestação cultural se movimenta nas espacialidades da microrregião bragantina articulando e desenvolvendo as práticas culturais de sua tradição, o que de alguma forma, mantém essa festa viva e presente culturalmente.

\section{DA LEVANTAÇÃO À DERRUBAÇÃO: O SABER/FAZER DA MARUJADA PELAS NARRATIVAS DAS CRIANÇAS}

A festa da Marujada de Tracuateua/PA, em devoção a São Benedito e São Sebastião, condensa muitos dos elementos vivenciados pela cultura dos negros africanos, pois nessa festa se observa que o grupo vivencia aspectos como a fé a devoção que estão imbricados na 
história dessa festividade por um simbolismo que se reverte nos saberes e fazeres dessa tradição para seus integrantes.

As crianças integrantes da marujada relatam que a marujada de Tracuateua é formada por muitos rituais os quais representam um saber e um fazer da festa. Ao Perguntar sobre o significado destes rituais, Nicole (09 anos) Rafael (11 anos) e Maria Guilhermina (12 anos) responderam que as danças e rezas são práticas que todos os marujos devem fazer, pois essas práticas estão relacionadas as suas promessas e dos demais devotos, visto que as crianças desenvolvem relações de um saber/fazer vivenciadas no seu cotidiano o que representa também atores sociais, nos seus mundos de vida e em suas e a infâncias (SARMENTO, 2000).

O sentido da marujada é vista por seus integrantes como uma continuação de uma tradição, na qual filhos e netos dão continuidade para resistência dessa manifestação. Tal tradição é vivida por meio dos seus saberes e fazeres que estão presentes em seu contexto. Esses saberes compõem e são desenvolvidos por um movimento educativo organizados pelos seus sujeitos, pois Brandão (2006, p. 17) ao falar de educação leva-nos a perceber que ela consiste e existe pela existência da própria vida. Seu desenvolvimento está presente em qualquer espaço que haja a circulação de saberes e fazeres, visto que:

[...] Ninguém escapa da educação. Em casa, na rua, na igreja ou na escola, de um modo ou de muitos todos nós envolvemos pedaços da vida com ela: para aprender, para ensinar, para aprender - e - ensinar. Para saber, para fazer, para ser ou para conviver, todos os dias misturamos a vida com a educação. (BRANDÃO, 2007, p. $03)$.

Nessa perspectiva, destacaremos alguns desses principais saberes/fazer observados e praticados pelas crianças como uma prática educativa vivida e compartilhada pela percepção delas sobre tais rituais.

a) A Levantação dos mastros: o início da festa

O sentido desse ritual está no fato de que é a partir da hora que sobe o mastro, começa a festa, e os integrantes da marujada são abençoados por São Benedito e São Sebastião. Tal ritual acontece no dia 18 (dezoito) de janeiro, dia que antecede a primeira homenagem aos santos da festa. A maioria dos integrantes e pessoas que acompanham a marujada geralmente se faz presente nessa levantação do mastro.

\footnotetext{
Na levantação do mastro começa a festa. [...] Os dois mastros é levantado, a gente tem que dançar, rezar. As pessoas batem palmas e as marujas dançam. Aí começa. (MARIA GUILHERMINA, 11 anos de idade - RODA DE CONVERSA JANEIRO/2016)

Quando levanta o mastro, é a hora de começar a festa. É muito legal. Aí tem gente que dança no dia de São Benedito, no dia de São Sebastião [...]. Era bom se a festa tivesse mais dias. (RAFAELA, 12 anos- RODA DE CONVERSA JANEIRO/2016).
}

A fala dos intérpretes fica claro que a levantação dos mastros simboliza o início da festa por ser uma ocasião importante. É o momento em que todos os marujos e marujas são convidados e convocados a participarem, seja para erguê-lo ou dançar ao seu redor. Os mastros são enfeitados nas residências dos juízes, ou seja, marujos ou marujas promesseiros ficam encarregados e têm a responsabilidade de organizarem a ornamentação e a alimentação que será servida na festa, inclusive organizando a levantação dos mastros. As figuras a seguir mostram o exato momento em que os marujos estão levantando o mastro de São Sebastião. 
Figuras 3 e 4 - Ornamentação e Levantação do mastro de São Sebastião

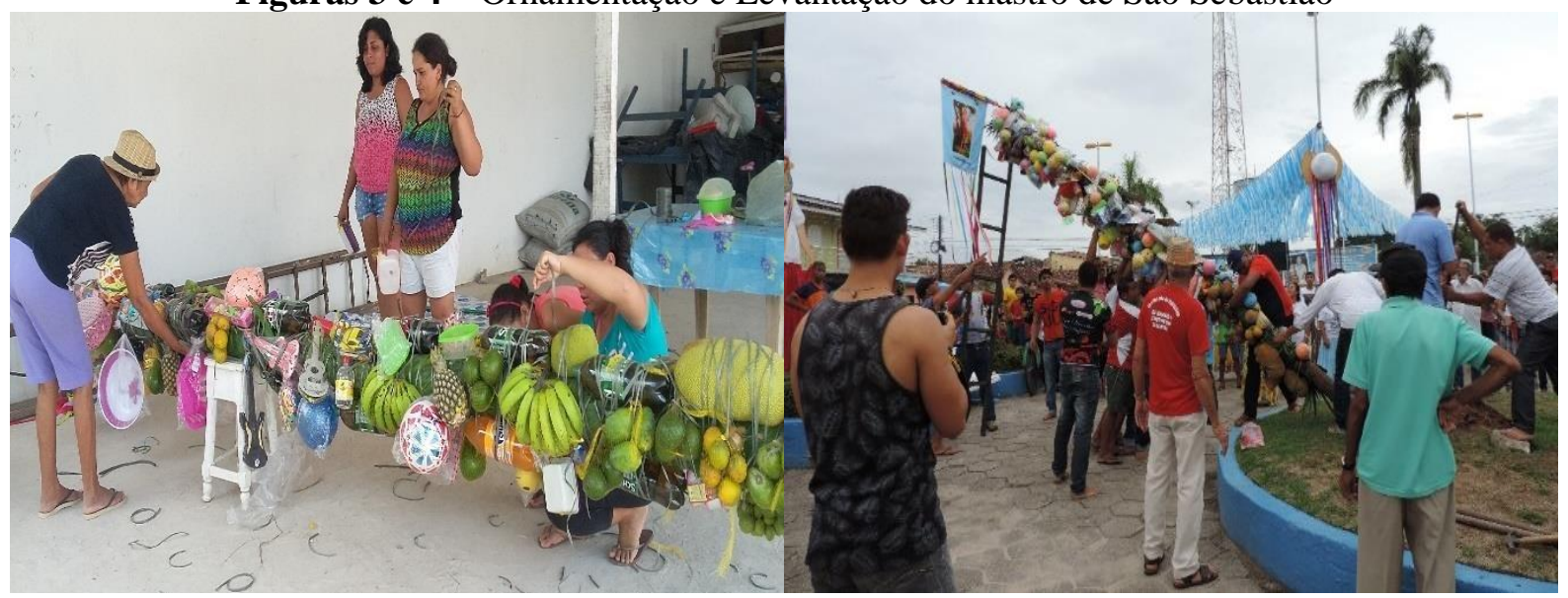

Fonte: Arquivo da Pesquisadora (2016)

Nas palavras de Debora (11 anos de idade) esse momento da arrumação do mastro representa muita devoção, pois "esses enfeites do mastro são os marujos que dão, porque eles fazem promessa pra dar. Quem faz a promessa, tem que oferecer".

b) Ritual alimentar:

O ritual do almoço e do jantar assumem diversos significados, entre os quais, se destaca a comunhão dos santos e seus devotos. Oferecer o almoço e o jantar oficiais da festa é a principal atribuição e responsabilidade dos juízes da festa. As refeições são servidas na parte interior do salão, onde se encontra o refeitório dos marujos e marujas, conforme figuras a seguir.

Figuras 5 e 6 - Ritual alimentar de São Sebastião e São Benedito

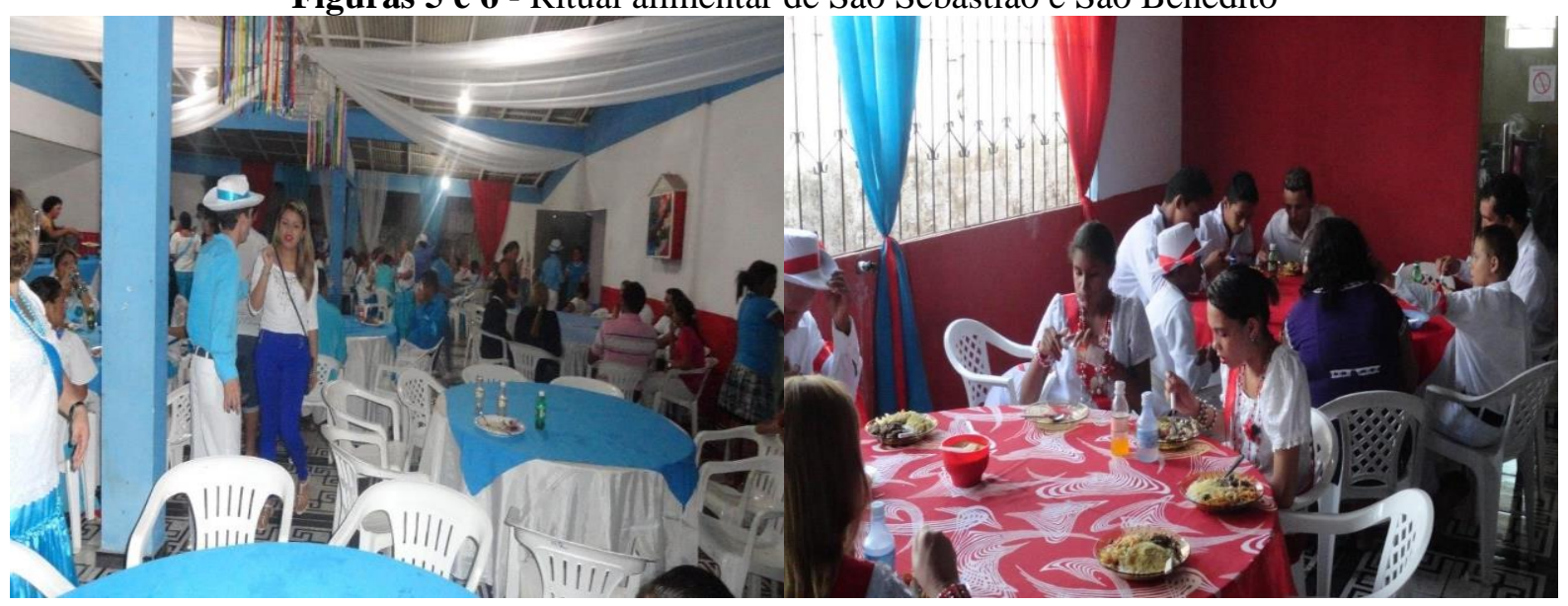

Fonte: Arquivo da Pesquisadora (Janeiro/2016)

Isso pode ser observado na fala das intérpretes Kiara (09 anos de idade) ao ressaltar a importância desse momento: "eu gosto também da hora do almoço, porque a gente come, tem até sobremesa. Todas as crianças comem" e Raiana (10 anos de idade) ao esclarecer que "Essa hora do almoço é sempre bom. Eles servem todo mundo, ninguém fica sem comer". Percebese que nesse ritual há dedicação dos juízes em servir aos marujos destacando a importância para a realização da festa. 
c) A procissão:

Após o almoço de São Sebastião, no segundo dia da festa, precisamente no dia 20 de janeiro, as expectativas dos participantes se voltam para a procissão. É nesse momento que os devotos manifestam sua devoção pelos santos São Benedito e São Sebastião, pois esse ritual da procissão marca a religiosidade e crença na interseção dos referidos santos, conforme o que segue.

Figura 7 - Procissão de São Benedito e São Sebastião

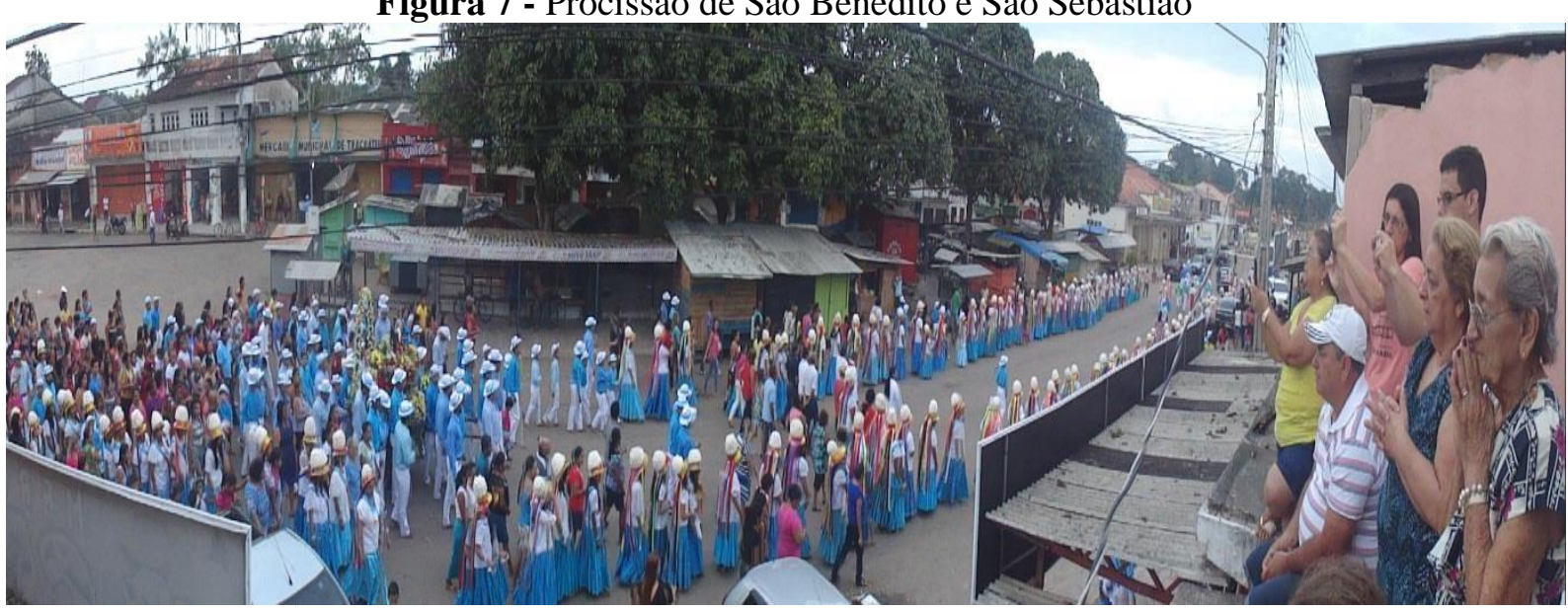

Fonte: Arquivo da Pesquisadora (Janeiro/2016)

Saindo da igreja matriz a procissão inicia as dezesseis horas e trinta minutos, percorrendo as principais ruas da cidade. Este percurso dura aproximadamente duas horas, após isso, a procissão retorna para a igreja. As marujas vão na caminhada formando duas filas nas laterais das ruas e os marujos levam o andor revezando-se entre eles na tarefa de carregar e proteger o andor durante toda a procissão, conforme pode ser observado na foto a seguir.

As crianças também acompanham a procissão, principalmente aquelas que são promesseiras. Elas não possuem um lugar especifico nesse ritual, ficam espalhadas pelo meio ou no colo dos adultos e normalmente estão acompanhas dos seus responsáveis. A procissão reúne toda a comunidade de devotos de São Benedito e São Sebastião. Ressaltamos que esse ritual representa um movimento de união, congregando pessoas das mais diferentes classes socioeconômicas, pois a caminhada é formada por marujos e marujas, religiosos, padres, autoridades, políticos e comunidade em geral.

Ao chegar na igreja, o andor com as imagens é recebido pelo padre, que abençoa os marujos e os participantes da procissão. Ainda nessa prática, os marujos e marujas ao chegarem em frente à igreja retiram seus chapéus da cabeça e colocam em direção as imagens dos santos, como forma de agradecimentos e em gesto de reverência. Isso pode ser comprovado pelas intérpretes Catarina (08 anos de idade), Kiara (09 anos) e Júlio (09 anos de idade):

Catarina: Eu danço faz tempo, porque eu pago promessa. (CATARINA, 08 anos de idade).

Kiara: Eu também acompanho a procissão, porque minha mãe fez uma promessa pra mim. (KIARA, 09 anos de idade).

Júlio: Eu pago promessa porque eu fiquei doente.ai todo ano eu acompanho a procissão. A minha mãe diz que é pra agradecer. Porque eu fiquei bom. (JÚLIO, 09 anos).

Descrever esse ritual da procissão é, sobretudo, falar da emoção expressa nos rostos dos fiéis, pois no momento em que o andor chega na igreja e ao som dos sinos, muitos rezam, 
muitos choram, muitos aplaudem e outros ficam de joelhos, talvez pedindo uma graça ou agradecendo outras. Certamente é um momento de emoção inesquecível.

d) Os rituais da dança

O estatuto da associação da marujada de Tracuateua (2000) define como danças tradicionais sete rituais de dança, tais como: a roda, o retumbão, o chorado, a mazurca, a valsa, o xote e a contradança. Essas dançam também representam o saber/fazer da marujada, pois as danças carregam uma simbologia e um movimento da história dessa tradição.

A roda marca o início e o fim dos rituais da dança e restabelece, portanto, a simbologia do mito de origem da marujada (SILVA, 1997). Informa o autor que a dança lembra a origem nos terreiros de macumba, pois se pede permissão, mesmo que simbolicamente, para iniciar a dança. Tal fato revive o rito de duzentos e onze anos, quando os negros pediam permissão aos seus senhores para dançar de casa em casa.

O ritual da roda é caracterizado pela circularidade dos gestos e movimentos, a dança é executada com os pés descalços, onde as mulheres marujas fazem um círculo no salão e dançam ao som dos instrumentos. Ao centro da roda dançam abraçados o capitão, capitoa e vice-capitoa que reverenciam ao público que assiste a dança. Nesse gesto, as autoridades da marujada informam e pedem licença para começar sua apresentação. Através dessa prática, pede-se licença simbolicamente aos presentes, autoridades, para iniciar a dança tal como, segundo a tradição, há quase dois séculos os negros pediam autorização aos seus senhores para dançar de casa em casa (SILVA, 1997, p. 209).

Marcada pela circularidade, na roda existe uma hierarquia que deve ser respeitada. Trata-se de uma coreografia formada por um círculo humano de marujas. Nesse ritual, as marujas são orientadas pela capitoa, que carrega nos braços um bastão ${ }^{3}$, e a vice-capitoa, as quais são superiores das demais marujas hierarquicamente. Elas conduzem e comandam as marujas mostrando os movimentos e a direção da dança pelo salão. Depois de alguns minutos de dança, as líderes saem da roda para ficarem no centro dela, conforme figuras a seguir.

Figuras 8 e 9 - O ritual de dança: a roda de São Benedito e São Sebastião

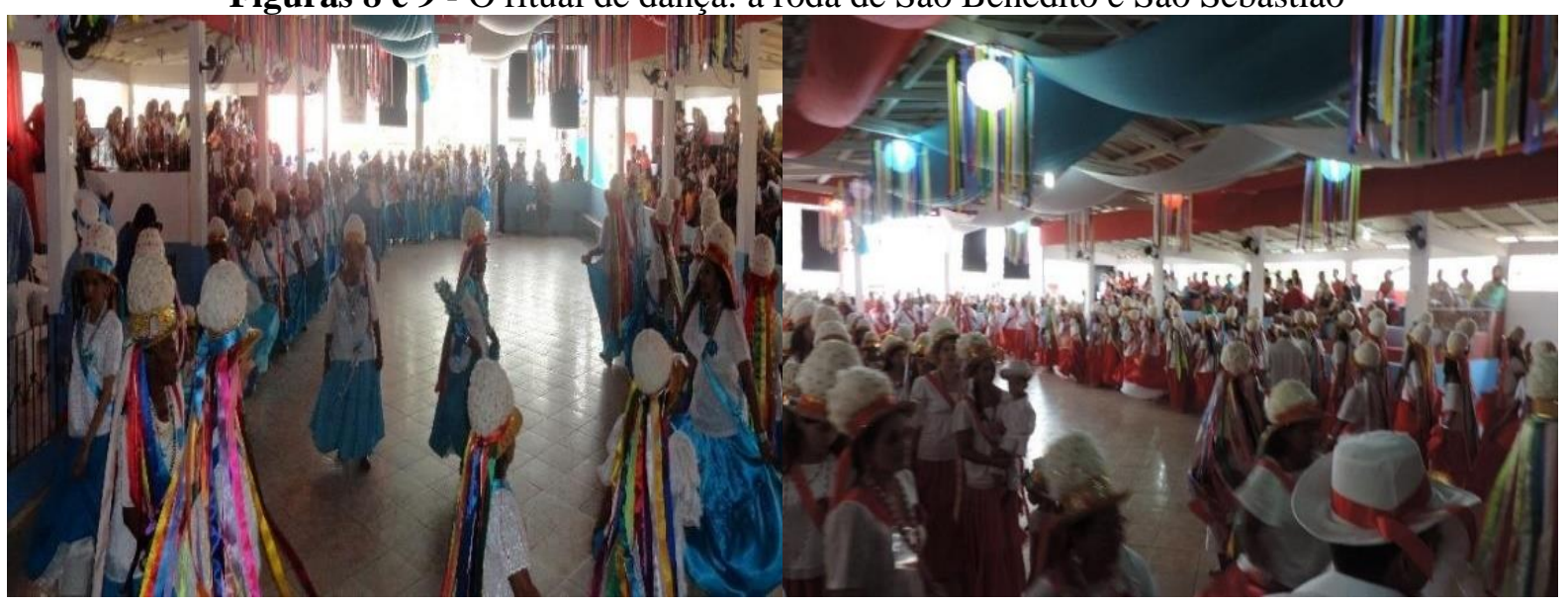

Fonte: Arquivo da Pesquisadora (Janeiro/2016)

Após a capitoa e vice-capitoa se dirigirem ao centro da roda, elas se juntam ao capitão e ambos fazem reverência aos juízes e juízas da festa, os quais permanecem sentados no salão esperando que todas as marujas da roda façam o mesmo gesto.

\footnotetext{
${ }^{3}$ Dois ramos de flores artificiais nas cores vermelha e azul que formam um só. Esse ramo simboliza a sua autoridade. Silva (1997) informa que esse bastão de flores faz alegoria ao chicote com que os senhores açoitavam seus escravos. Era o símbolo do poder dos que estavam sob sua autoridade.
} 
O retumbão e o chorado:_O primeiro se constitui na sequência dos rituais. É o segundo ritmo dança da marujada e representa uma situação de "margem vivida pelo homem", pois o marujo, a uma condição de centro, isto é, ao contrário da roda, nele é o marujo quem inicia o ritual. Como ressalta a fala do intérprete Júlio (09 anos de idade) quanto sua preferência pelo ritual: "Eu gosto mais do retumbão. [...]. Ah! Quando eu escuto o retumbão, eu quero logo dançar! O retumbão é bonito, é legal". Nessa dança é sempre o marujo que inicia. Depois a gente chama a maruja" (RODAS DE CONVERSA - JANEIRO/2016).

Na ordem das apresentações o chorado é o terceiro ritual, isto é, a terceira dança. É uma variação do retumbão, a diferença está no ritmo que é mais lento e sensual e, no número de pares que se apresentam. Nessa dança somente um casal se apresenta por vez. Assim, como no retumbão é o marujo que dá início ao ritual. Para Bordallo da Silva (1981) e Silva (1997), o retumbão e o chorado possui compasso musical e ritmo do lundu, modificado progressivamente da senzala ao salão aristocrático. Descrevem que o termo retumbão tem origem portuguesa, pelo fato de que era possível escutar o ritmo de locais distantes, onde o som "retumbava". A orquestra para entoar a dança, pois não há canto, compõem-se de tambores grandes, pandeiros, cuíca (onça), rabeca, viola, cavaquinho e violino. Esses ritmos apresentam "elementos que lembram não apenas o lundu", isto é, a dança em roda ou em círculos; "o bailado aos pares; os movimentos do corpo; o castanholar dos dedos, a marcação das palmas e o uso da viola" (SILVA, 1997, p. 219), conforme figuras abaixo.

Figuras 10 e 11- Ritual de dança: o retumbão e o chorado

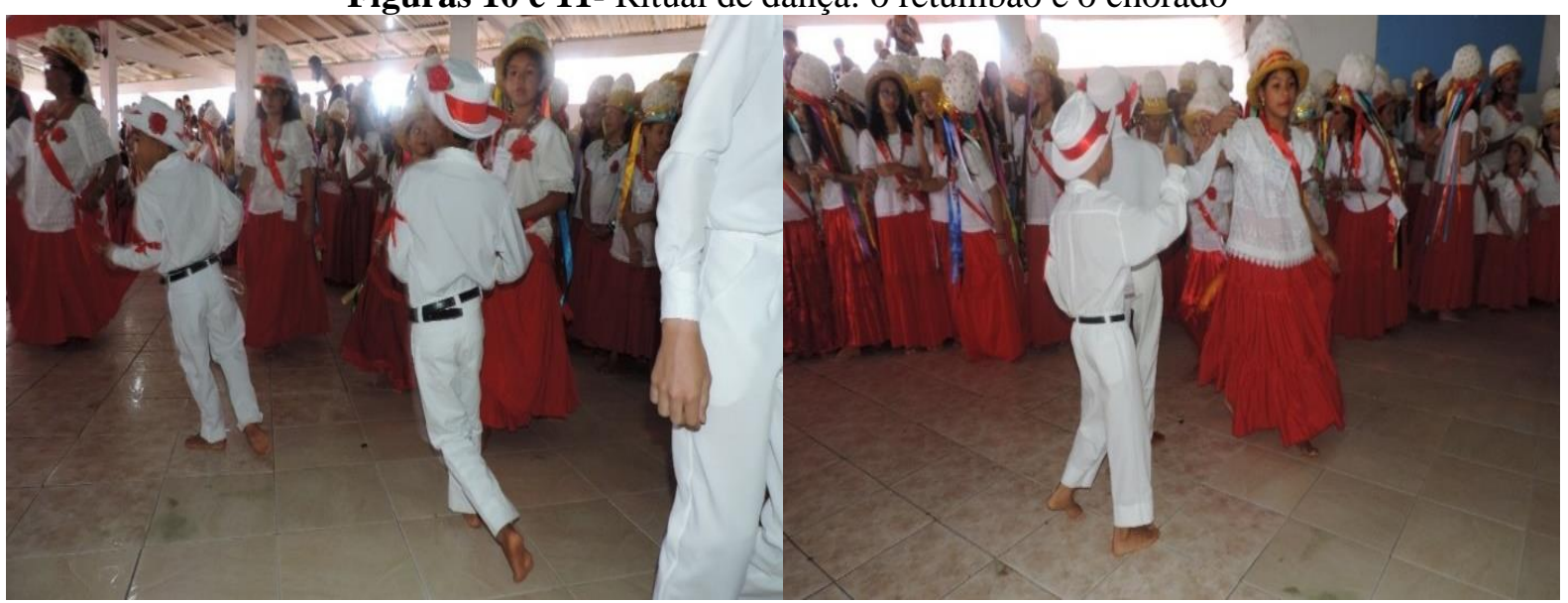

Fonte: Arquivo da Pesquisadora (Janeiro/2016)

Ao observar esses três primeiros rituais da marujada e ao considerar o que diz Silva (1997, p. 219), nota-se que eles apresentam em suas coreografias, elementos, passos e gestos que lembram o lundu, a dança em roda ou em círculos, embora na marujada esse bailado seja mais ameno, "talvez por ter sofrido algum tipo de resistência eclesiástica".

A mazurca, a valsa e o xote: Esses "constituem como danças tardias, ou seja, foram incorporadas posteriormente à estrutura ritualística da marujada". A mazurca e a valsa possui características europeias, especificamente do século XIX, mas ao fazer parte dos rituais da marujada assumiu características próprias como dança em roda e o uso dos pés descalços. (SILVA, 1997).

e) A derrubação do mastro e a varrição da festa:

A derrubada dos mastros representa o final da festa, conforme relata a intérprete Débora (11 anos): "Quando chega a varrição a gente fica triste, porque já vai terminar a festa" e Maria Guilhermina (12 anos): 
$\mathrm{Na}$ hora que derrubam os mastros a gente começa a danças ao redor deles. Depois a gente fica esperando os brinquedos, (...) porque eles são dados para as crianças. Os brinquedos dos santos. Mais todos ficam meio triste porque a festa tá acabando. Ai tem que esperar o outro ano. (RODA DE CONVERSA/JANEIRO/2016).

A derrubação dos mastros, conforme falam as crianças, significa que àquele ciclo se encerra para organização de ciclo vindouro.

Figura 12 - Derrubação do mastro

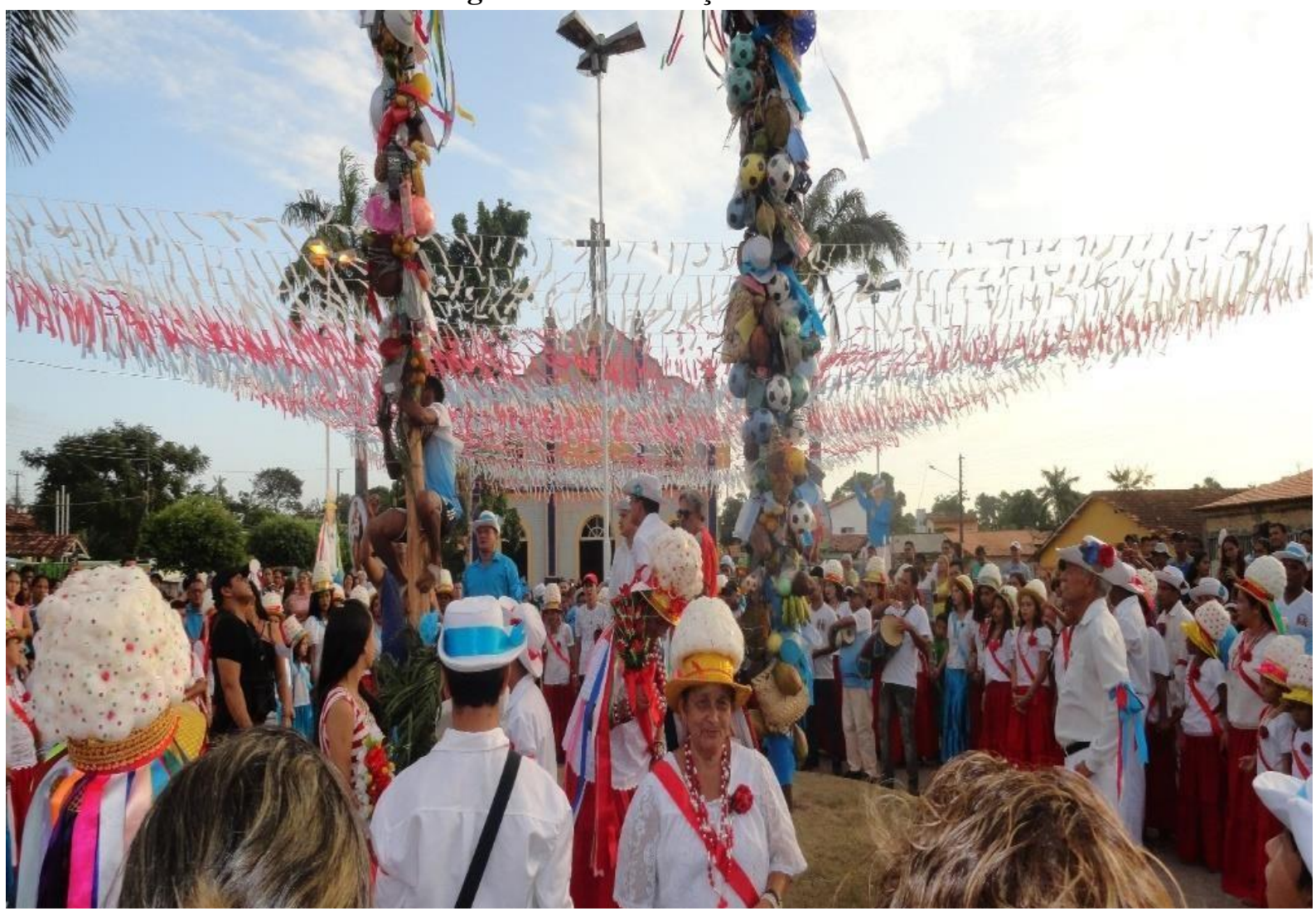

Fonte: Arquivo da Pesquisadora (Janeiro/2016)

Na noite da derrubada dos mastros, data do dia 21 de todos os anos, os marujos e marujas são convidados para o ritual da varrição todos devem varrer a festa, isto implica dizer que os marujos e marujas varrem, no sentido de repetir todos os rituais de dança. Nesse ritual da varrição qualquer pessoa pode participar, desde que ela esteja vestida adequadamente segundo as exigências da associação.

No final da festa, as pessoas presentes aplaudem e as marujas, ao som dos instrumentos musicais, fazem uma roda ao redor dos mastros e dançam. Em seguida todos se dirigem ao salão da marujada para juntos varrerem a festa, conforme explicam Maísa e Rafaela (12 anos): "(...) depois da derrubação dos mastros a gente varre a festa. Nesse dia todos dançam. E a gente pode escolher qualquer roupa a de são Benedito ou a de São Sebastião".

Podemos analisar, por meio desses saberes e fazeres vivenciados pela criança que a educação está presente nesse contexto na festa da marujada de Tracuateua/PA. Uma educação que está pautada na diversidade do conhecimento, de solidariedades entre os sujeitos e em um processo de compartilhamento e coparticipação de saberes por seus membros. Em outras palavras a educação "é um triplo processo: um processo de humanização, de socialização, de subjetivação/singularização" (CHARLOT, 2013, p. 167).

Brandão (2002) na sua análise entre cultura e educação, deixa claro que a educação 
não existe só na escola ou nas instituições de ensino,

Não há uma forma única nem um único modelo de educação; a escola não é o único lugar onde ela acontece e talvez nem seja o melhor; o ensino escolar não é a sua única prática e o professor profissional não é o seu único praticante. (BRANDÃO, 2006, p. 04).

Por isso, a narrativas das crianças sobre suas experiências e vivencias na marujada revela esse espaço como um lugar de aprendizagens de humanidades, porque as crianças também instigam e protagonizam as práticas em seus contextos.

\footnotetext{
Não são apenas os adultos que intervêm junto das crianças, mas as crianças também intervêm junto dos adultos. As crianças não recebem apenas uma cultura constituída que lhes atribui um lugar e papéis sociais, mas operam transformações nessa cultura, seja sob a forma como a interpretam e integram, seja nos efeitos que nela produzem, a partir das suas próprias práticas (SARMENTO, 2000, p. 152).
}

Dessa forma, partindo da diversidade de conhecimento construídos no cotidiano da marujada, identificou-se saberes e fazeres inerentes a festa vivenciados e partilhados do/pelo movimento entre marujos e marujas de diferentes gerações por meio da escuta, da observação e da oralidade. Nesse movimento da cultura, onde ela circunscreve as expressões da criança de forma geral, como "as ideias, os valores, e as emoções são produtos culturais manufaturados", ou seja, são tecidas pelas mãos dos sujeitos, sendo que para a compreensão dessas expressões ou desses signos é necessário compreender o significado e chegar até "os conceitos específicos das relações entre eles" (GEERTZ, 2014, p. 36-37). Em outras, palavras podemos dizer que os saberes e fazeres representam processos educativos vinculados as diversas práticas culturais, sendo estas a representatividade das expressões humanas em seus mais variados contextos caracterizando, dessa forma, as manifestações culturais como espaços de aprendizagens.

\section{CONSIDERAÇÕES FINAIS}

Este artigo procurou analisar o saber/fazer na festa da marujada em Tracuateua/PA por meio das falas das crianças, que chamamos de narrativas, numa perspectiva cultural que envolve a circulação de saberes e, por conseguinte uma relação de aprendizagem, onde seus sujeitos relacionam-se entre si e sob práticas constituídas por um simbolismo religioso que revelam os saberes e sua relevância para a diversidade educacional amazônica.

As concepções teóricas levantadas e construídas nesta pesquisa nos possibilitaram buscar novas compreensões sobre a construção científica. Essas concepções tornaram-se essenciais para a compreensão de que uma pesquisa não se faz só, mas ela é o resultado de uma construção coletiva para aquilo que se propõem apresentar. Desse modo, este trabalho foi desenvolvido com as crianças participantes da marujada de Tracuateua, que demonstraram as suas relações com os saberes que estão inscritos no contexto dessa festa.

Para atingir nossos objetivos propostos nos apropriamos de referenciais teóricos que nos orientaram sobre o objeto de pesquisa e sobre os sujeitos que escolhi pesquisar, a fim de compreender respostas para muitas indagações, uma vez que fazer pesquisa com crianças requer compreender que elas são sujeitos protagonistas. Assim, foi possível perceber os diferentes saberes e fazeres que perpassam as festas na Amazônia pelo olhar da criança que se inserem e possuem suas percepções nesses contextos, pois elas adentram nesses ensinamentos desde muito cedo o que também torna possível a compreensão delas sobre determinados fazeres e saberes da marujada. A criança consegue compreender, da maneira dela, todos os processos organizacionais e simbólicos desta manifestação cultural. 
De modo geral, foi possível perceber que as crianças que participam dessa manifestação cultural aprendem e compartilham saberes. Essa aprendizagem é desenvolvida por meio da escuta, do fazer, do compartilhar com os outros e pela própria vivência no grupo. São aprendizagem que se desenvolvem a partir de processos educativos que decorrem da produção e da circulação dos saberes.

\section{REFERÊNCIAS}

ALVES, Laura Maria Silva Araújo. A infância em construção: as fontes de investigação. In: Pesquisa e educação na Amazônia: reflexões epistemológicas e políticas/ Sônia Maria da Silva Araújo, Laura Maria Silva Araújo Alves, Sônia de Jesus Nunes Bertolo (Orgs.) Belém: EDUEPA, 2014.

AMORIN, Ana Karine Jansen. Um fogo que se deita no mar: um estudo sobra a marujada do município de Quatipuru/PA. 2008. Tese (Doutorado em Artes Cênicas) - Universidade Federal da Bahia, 2008.

BARDIN, Laurence. Análise de conteúdo. Lisboa: Edições Setenta, 1994. 226 p.

BRANDÃO, Luis Carlos. O que é Educação? (Coleção Primeiros Passos - n 20). São Paulo: Brasiliense, 2007.

BRANDÃO, Luis Carlos. Educação como Cultura. São Paulo: Cortez, 2002.

CHARLOT, Bernard. Da relação com o saber: elementos para uma teoria. Porto Alegre: Artes Médicas Sul, 2013.

COHN, Clarice. Antropologia da Criança / Clarice Conh - Rio de Janeiro: Jorge Zahar Ed., 2005

FERNANDES, José Guilherme dos Santos. Pés que Andam Pés que Dançam. Memória, identidade e religião cultural na esmolação e marujada de São Benedito. Coleção Saberes Amazônicos. Belém: EDUEPA. 2011.

GEERTZ, Clifford. A interpretação das culturas. $1^{\text {a }}$ Ed. 13 Reimp. Rio de Janeiro. LTC, 2014. 323 p.

IBGE. Instituto Brasileiro de Geografia e Estatística. Censo 2010. Disponível em: http://www.ibge.gov.br/. Acesso: 24 de jan. de 2016.

LAVILLE, Christian.; DIONNE, Jean. A construção do saber. Belo Horizonte: UFMG, 1999. $340 \mathrm{p}$.

KRAMER, Sonia. Currículo de Educação Infantil e a formação dos profissionais de creche e pré-escola: questões teóricas e polêmicas. In: Por uma política de formação do profissional de Educação Infantil/MEC/SEF/COEDI - Brasília: MEC/SEF/DPE/COEDI, 1994. p.16-31.

MINAYO, Maria Cecília. Pesquisa social: teoria, método e criatividade. $28^{\mathrm{a}}$ edição. Petrópolis. RJ/2015 
OLIVEIRA, Ivanilde Apoluceno de; MOTTA - NETO, João Colares da. A construção de categorias de análises na pesquisa em educação. In: MARCONDES, Maria Inês; OLIVEIRA, Ivanilde Apoluceno de; TEIXEIRA, Elizabete (org.). Abordagens teóricas e construções metodológicas na pesquisa em educação. Belém: EDUEPA, 2011.

PINHEIRO, Márcio Duarte. Elaborador das imagens de mapas. Janeiro/2016.

REIS, Maria Helena de Aviz. Marujada de Tracuateua/PA: Um olhar sobre as manifestações culturais e religiosas na Festividade de São Benedito e São Sebastião. In: I CONGRESSO LUSÓFONO DE CIÊNCIAS DAS RELIGIÕES, 2015, Lisboa. Anais [...]Universidade Lusófona de Humanidades e Tecnologias, Lisboa - Portugal, 2015

SARMENTO, Manoel Jacinto. A infância como construção social. In: PINTO, Manuel e SARMENTO, Manuel Jacinto (coord.). As crianças: contexto e identidades. Portugal: Universidade do Minho (Centro de Estudos da Criança), 1997.

SILVA, Armando Bordallo da. Contribuição ao estudo do folclore amazônico na zona Bragantina. Belém, 2 ed. 1981. Coleção Victorino Chermont de Miranda. 93 p.

SILVA, Dedival Brandão. Os Tambores da Esperança: um estudo sobre cultura, religião, simbolismo e ritual na festa de São Benedito da cidade de Bragança. Falangola Editora. 1997.

THOMPSON, John B. Ideologia e Cultura Moderna: teoria social crítica na era dos meios de comunicação de massa. Petrópolis, RJ: Vozes: 1995. 